\title{
Formulation and evaluation of transdermal films of ondansetron hydrochloride
}

\begin{abstract}
Transdermal delivery of ondansetron hydrochloride is one of the promising ways to maximize the therapy in contrast to oral delivery. Current investigation efforts are focused in formulating the ondansetron hydrochloride matrix-type transdermal film by incorporating hydrophilic and hydrophobic polymers. In this study, ondansetron hydrochloride transdermal films were prepared using solvent evaporation technique and characterized for film physical parameters, in vitro drug release and ex vivo permeation studies through rat skin and also subjected to the differential scanning calorimetry and stability studies. The percentage drug release form both in vitro drug release $(99.12 \pm 0.96 \%)$ and ex vivo permeation studies $(73.28 \pm 0.92 \%)$ were found to be highest for formulation carrying PVA: PVP in ratio 1:4 (F6) due to the hydrophilic nature of the polymers and pore formation due to leaching of PVP. The release profile of the best formulations F6 ( $\mathrm{r} 2=0.999$ for Higuchi) indicated that the permeation of the drug from the patches was governed by diffusion mechanism. The calculated flux and permeability coefficients of F6 formulation was found as $5.95 \mu \mathrm{g} / \mathrm{cm} 2 / \mathrm{h}$ and 0.748 The calculated similarity index value between dissolution profiles of F6 formulation before and after storage was found to be 88.76 indicates similarity between the dissolution profile before and after storage. Above results indicate that the formulation of transdermal films of ondansetron hydrochloride using PVA and PVP combination is a suitable way for therapeutic benefit.
\end{abstract}

Keywords: diffusion, Ex vivo permeation studies, hydrophilic, hydrophobic, solvent evaporation technique
Volume 3 Issue 4 - 2017

\author{
Faseen Mohd,' Laxmi Samhitha Bontha, ${ }^{2}$ \\ Vijaya Kumar Bontha, ${ }^{2}$ Sateesh Kumar \\ Vemula ${ }^{1,3}$ \\ 'Department of Pharmaceutics, Chaitanya College of Pharmacy \\ Education and Research, India \\ ${ }^{2}$ Department of Pharmaceutics, Jangaon Instiute of \\ Pharmaceutical Sciences, India \\ ${ }^{3}$ Department of Pharmaceutics, MAK College of Pharmacy, India
}

Correspondence: Sateesh Kumar Vemula, Department of Pharmaceutics, Chaitanya College of Pharmacy Education and Research, Kishanpura, Hanamkonda, Warangal,Telangana, India-50600I,Email vemulasatishI5@gmail.com

Received: March 17, 2017 | Published: June 16, 2017
Abbreviations: PVA, polyvinyl alcohol; PVP, polyvinyl pyrrolidone; OSH, ondansetron hydrochloride; 5- $\mathrm{HT}_{3}, 5$-hydroxytryptamine type 3; DS, degree of swelling; DSC, differential scanning calorimetry; EC, ethyl cellulose

\section{Introduction}

Development of alternative drug delivery technologies to oral delivery is not only to amplify the efficiency and safety of drug delivery but also to provide the more patient convenience. Transdermal drug delivery systems are described as self-contained discrete dosage forms intended to skin application to deliver the drugs through skin at controlled rate to the systemic circulation (USP 25). Transdermal delivery of drugs intended either for localized treatment of tissues or for systemic therapy. The major challenge in formulation of the transdermal products is not only to optimize the flux through the skin into the systemic circulation but also to reduce the retention and metabolism of the drug in the skin. ${ }^{1}$

Real points of interest of the transdermal drug delivery over the oral route such as improving patient compliance in long term therapy, bypassing first-pass metabolism, sustaining drug delivery, maintaining a constant and prolonged drug level in plasma, minimizing inter and intra patient variability, and making it possible to interrupt or terminate treatment when necessary. ${ }^{2,3}$ Till date, more than 20 drugs alone or in combination have been launched into transdermal products worldwide and remaining are still in the development phases (phase II to registration). Some of the research example drugs that formulated as matrix based transdermal formulations are metoprolol tartrate, ${ }^{4}$ labetolol hydrochloride, ${ }^{5}$ ephedrine, ${ }^{6}$ ketoprofen, ${ }^{7}$ triprolidine ${ }^{8}$ nitrendipine ${ }^{9}$ and propranolol. ${ }^{10}$

Ondansetron hydrochloride $(\mathrm{OSH})$ is a serotonin $\left(5-\mathrm{HT}_{3}\right)$ receptor antagonist that is used in prevention of chemotherapy and radiotherapy-induced nausea and vomiting. In the present study, an effort was put to formulate OSH transdermal film using solvent evaporation technique to maximize the therapy. OSH is considered as the ideal drug for transdermal delivery due to its low molecular weight, shorter half-life (5-6h), poor bioavailability (60\%) and good permeability. ${ }^{11}$ Hence the present study is intended to formulate the OSH transdermal film to gain the prolonged drug release time and also to reduce the frequency of administration to improve patient compliance. When compared to the previous studies on $\mathrm{OSH},{ }^{12}$ the present study is aimed to prepare films with simple method using combination of combination of hydrophilic and hydrophobic polymers. The rationale behind the selection of ethyl cellulose/PVA/ PVP/eudragit is easily available at low cost, good film formers and able to study the effect of both hydrophilic and hydrophobic nature on drug release. Hence the present study is aimed to prepare OSH transdermal films using combination of above polymers to improve bioavailability

\section{Materials and methods}

\section{Materials}

Ondansetron hydrochloride was a gift from Sun Pharmaceuticals (Baroda, India). All other chemicals were purchased from SD Fine Chemicals (Mumbai, India). All the polymers received were of 
pharmaceutical grade. Other materials and solvents used were of analytical grade.

\section{Preparation of trans-dermal films}

Transdermal films containing OSH were prepared by the mercury substrate solvent evaporation technique..$^{13}$ The polymers, ethyl cellulose, eudragit $\mathrm{RL}_{100}$, eudragit $\mathrm{RS}_{100}$, polyvinyl pyrrolidone and polyvinyl alcohol were taken in a weighing bottle. About $10 \mathrm{ml}$ of solvent mixture of chloroform/acetone/water were added and shaked to prevent the formation of lumps and then kept aside for swelling of polymers. And after complete solubilization of polymers in mixture of solvent, added required quantity of dibutyl phthalate and menthol to this mixture, and stirred. Finally weighed quantity of OSH was dissolved in $5 \mathrm{ml}$ of solvent mixture, added to the polymer solution and mixed well. It was set-aside for some time to exclude any entrapped air and was then transferred into a previously cleaned petridish $\left(70.00 \mathrm{~cm}^{2}\right)$ and then this was kept aside for solvent evaporation. The rate of solvent evaporation was controlled by inverting a glass funnel over the petridish. After $12 \mathrm{~h}$, the dried films were taken out and stored in a desiccator. The composition of the patches is given in Table 1. The films were stored between sheets of wax paper in a desiccator.

Table I Formulation of OSH transdermal films

\begin{tabular}{lllll}
\hline $\begin{array}{l}\text { *Formulation } \\
\text { code }\end{array}$ & EC:PVP & PVA:PVP & ED RL:RS & Solvent \\
\hline FI & $0 \mathrm{I}: 0 \mathrm{I}$ & - & - & Chloroform \\
F2 & $0 \mathrm{I}: 02$ & & - & Chloroform \\
F3 & $0 \mathrm{I}: 04$ & - & - & Chloroform \\
F4 & - & $0 \mathrm{I}: 0 \mathrm{I}$ & - & Water \\
F5 & - & $0 \mathrm{Il:02}$ & - & Water \\
F6 & - & $0 \mathrm{I}: 04$ & - & Water \\
F7 & - & - & $0 \mathrm{I}: 01$ & Acetone \\
F8 & - & - & $01: 02$ & Acetone \\
F9 & - & - & $01: 04$ & Acetone \\
\hline
\end{tabular}

Note:*Each transdermal film contains $8 \mathrm{mg}$ of OSH, $5 \%$ menthol as permeation enhancer and $25 \%$ dibutyl phthalate as plasticizer. EC-Ethyl cellulose; PVAPolyvinyl alcohol; PVP-Polyvinyl pyrrolidone; EDRL-Eudragit $\mathrm{RL}_{100}$; EDRS: Eudragit $\mathrm{RS}_{100}$

\section{Physical evaluation of trans-dermal films}

The prepared transdermal films were visually inspected for smoothness and clarity. The thickness of the films was assessed at three different points using screw gauze. For each formulation, three randomly selected films were used. In weight variation test, three disks of $2 \times 2 \mathrm{~cm}^{2}$ was cut and weighed on electronic balance for weight variation test. The folding endurance was measured manually for the prepared transdermal films. A strip of the films $(4 \times 3 \mathrm{~cm})$ was cut evenly and repeatedly folded at the same place till it is broken. To evaluate the drug content uniformity, the film of area $3.83 \mathrm{~cm}^{2}$ was cut and dissolved in phosphate buffer $\mathrm{pH}$ 7.4. Then solvent ethanol and dichloromethane, to make polymer soluble, were added to the mixture and the remaining volume was made up with phosphate buffer to $100 \mathrm{ml}$. Then $1 \mathrm{ml}$ was withdrawn from the solution and diluted to $10 \mathrm{ml}$. The absorbance of the solution was taken at $310 \mathrm{~nm}$ and concentration was calculated. By correcting dilution factor, the drug content was calculated. ${ }^{11}$

\section{Moisture content and Moisture uptake}

The prepared films were weighed individually and kept in a desiccators containing fused calcium chloride for $24 \mathrm{~h}$. The films were reweighed until a constant weight was obtained. Moisture content was calculated in percentage based on the difference between the initial and the constant final weights of the patches.

The percent moisture absorption test was carried out to check the physical stability and integrity of the films at high humid conditions. In the present study the moisture absorption capacities of the film were determined in the following manner. The films were placed in the desiccators containing $200 \mathrm{ml}$ saturated solution of potassium chloride, to get the humidity inside the desiccators at $84 \%$ RH. After 3 days the films were taken and weighed the percentage moisture absorption of the patch was found. ${ }^{14}$

$$
\text { Percentage moisture absorbed }=\frac{\text { Final weight }- \text { Initial weight }}{\text { Initial weight }} \times 100
$$

\section{Water vapour transmission rate}

Glass vials of $5 \mathrm{ml}$ capacity were washed thoroughly and dried to a constant weight in an oven. About $1 \mathrm{~g}$ of fused calcium chloride was taken in the vials and the polymer films of $3.83 \mathrm{~cm}^{2}$ were fixed over the brim with the help of an adhesive tape. Then the vials were weighed and stored in a humidity chamber of $80-90 \%$ RH condition for a period of $24 \mathrm{~h}$. The vials were removed and weighed at $24 \mathrm{~h}$ time intervals to note down the weight gain. ${ }^{15}$

$$
\text { Water Vapor Transmission Rate }=\frac{\text { Final weight }- \text { Initial weight }}{\text { Time } \times \text { area }}
$$

\section{Swelling study}

Completely dried films with a specified area $\left(3.83 \mathrm{~cm}^{2}\right)$ were weighed and put in desiccators for $24 \mathrm{~h}$. They were removed and exposed to relative humidity conditions of $75 \%$ (containing saturated solution of sodium chloride) in desiccators. Weight was taken on a single pan balance periodically until a constant weight was obtained. The swelling capacity of the films (in weight \%) was calculated in terms of percentage increase in weight of membrane over the initial weight of the specimen. The experiments were carried out in triplicate and the average values were used for the calculation.

The percentage degree of swelling (DS) was calculated as

$$
\operatorname{DS}(\%)=\mathrm{W}_{\mathrm{s}} ? \mathrm{~W}_{\mathrm{d}} / \mathrm{Wd} \times 100
$$

Where,

$\mathrm{W}_{\mathrm{s}}$ and $\mathrm{W}_{\mathrm{d}}$ indicate the weight of the swollen and dry membranes respectively. ${ }^{4}$

\section{In vitro permeation studies using dialysis membrane}

In vitro permeation of OSH from transdermal films through dialysis membrane (Hi-Media) with molecular weight cut off of 12000 was studied. The membrane was mounted over a Franz diffusion cell and then placed the transdermal film. The receiver compartment of the diffusion cell was filled with $15 \mathrm{ml}$ of phosphate buffer $\mathrm{pH} 7.4$ 
and the setup was placed over a magnetic stirrer at $37^{\circ} \mathrm{C}$. Samples of $3 \mathrm{ml}$ were withdrawn and replenished immediately from the receiver compartment at 1,2, 3, 4, 6 and 12h. They were stored in refrigerated condition till the analysis was performed. The content of OSH in the samples was analyzed by UV-Visible spectrophotometer at $310 \mathrm{~nm} .{ }^{11}$

\section{Ex vivo rat skin permeation studies}

A full thickness of skin was excised from dorsal site of dead rat and was washed with water. The fatty tissue layer was removed by using nails of fingers. The outer portion with hairs was applied with depilatory and allowed to dry. With the help of wet cotton the hairs were scrubbed and washed with normal saline solution. The skin was kept in normal saline solution in refrigerator until skin was used for diffusion study. Prior to use, the skin was allowed to equilibrate with room temperature. Then skin was mounted between donor and receptor compartment of cell. The skin was clamped in such a way that the dermal side will be in contact with receptor medium. Phosphate buffer $\mathrm{pH} 7.4$ was used as receptor solution. The volume of diffusion cell was $15 \mathrm{ml}$ and stirred with magnetic bead. The temperature was maintained at $37^{\circ} \mathrm{C}$ with the help of hot plate. ${ }^{5}$ The diffusion was carried out for $12 \mathrm{~h}$ and $3 \mathrm{ml}$ sample was withdrawn at an interval of $1 \mathrm{~h}$ up to $6 \mathrm{~h}$ and finally at $12 \mathrm{~h}$. The same volume of phosphate buffer $\mathrm{pH}$ 7.4 was added to receptor compartment to maintain sink conditions and the samples were analyzed at $310 \mathrm{~nm} .{ }^{11}$

\section{Determination of flux and release kinetics}

The flux (J) of OSH was calculated from the slope of the plot of cumulative amount of drug permeated per $\mathrm{cm}^{2}$ of skin at steady state against the time using linear regression analysis. ${ }^{4}$

The steady state permeability coefficient $(\mathrm{Kp})$ of the drug through rat epidermis was calculated by using the following equation:

$$
\mathrm{K}_{\mathrm{p}}=\mathrm{J} / \mathrm{C}
$$

Where, $\mathrm{J}=$ flux $\left(\mu \mathrm{g} / \mathrm{cm}^{2} / \mathrm{hr}\right)$;

$\mathrm{C}=$ concentration of drug in the transdermal film.

The data obtained from the above permeation studies was fitted to zero order, first order and Higuchi models to explain the pattern and the release mechanism from the formulations. ${ }^{16}$ Korsmeyer -Peppas model is one of the mathematical expressions, used to understand the mechanism of drug release from these formulations. ${ }^{17}$

The Korsmeyer-Peppas equation is as follows;

$$
\mathrm{Mt} / \mathrm{M} \alpha=\mathrm{Ktn}
$$

In which,

$\mathrm{Mt} / \mathrm{M} \alpha$ is the fractional amount of drug released at time $\mathrm{t}$,

$\mathrm{K}$ is a kinetic rate constant and

$\mathrm{n}$ is the diffusional exponent that characterizes the mechanism of drug release.

\section{Drug-polymer interaction studies}

To study the possible interaction between drug and polymers, Differential scanning calorimetry (DSC) study was carried out on pure drug and the best formulation and the thermograms were obtained using DSC (Perkin-Elmer, Shelton, U.S). The analyses were performed under nitrogen (nitrogen flow rate $50 \mathrm{ml} / \mathrm{min}$ ) in order to eliminate oxidative and pyrrolytic effects at a standard heating rate of $15^{\circ} \mathrm{C} /$ minute over a temperature range of $50^{\circ} \mathrm{C}-350^{\circ} \mathrm{C}$.

\section{Stability studies}

Stability studies conducted to review the OSH stability in the prepared transdermal films as said by ICH guidelines. The sample films were sealed in aluminium packaging coated inside with polyethylene, and three sets were stored in stability chamber $\left(40 \pm 2^{\circ} \mathrm{C}\right.$ and $75 \pm 5 \%$ $\mathrm{RH})$ for six months. ${ }^{18,19}$ Samples were collected after three months of storage and evaluated. The results were under gone to statistical analysis with the help of paired t-test to test the significance of difference at 0.05 level of significance. Then the similarity index was calculated between permeation rates of best formulation before and after storage to prove..$^{20,21}$ The similarity factor $\left(\mathrm{F}_{2}\right)$ is a logarithmic reciprocal square root transformation of the sum of squared error and is a measurement of the similarity in the percent (\%) of dissolution between the two curves. It is calculated using the following formula.

$$
\mathrm{f}_{2}=50 \cdot \log \left\{\left[1+(1 / \mathrm{n}) \sum_{\mathrm{t}}=1^{\mathrm{n}}\left(\mathrm{R}_{\mathrm{t}-\mathrm{T}_{\mathrm{t}}}\right)^{2}\right]^{-0.5} \cdot 100\right\}
$$

\section{Results}

\section{Physical evaluation of transdermal films}

All the prepared transdermal films evaluated for different physical parameters and they were showed in Table 2. In these evaluations, weight variation was found in the range of $64.21 \pm 1.4$ to $68.36 \pm 1.8$ $\mathrm{mg}$ and thickness was found to be between $24 \pm 1.6$ to $46 \pm 1.8 \mu \mathrm{m}$. The folding endurance measures the ability of patch to withstand rupture and it was found to be in the range of $71 \pm 0.9$ to $80 \pm 2.2$. Estimation of drug content was found to be in the range of $96.75 \pm 0.48 \%$ to $99.83 \pm 0.74 \%$ indicating that the drug is uniformly distributed. The values of $\%$ Swellability, water vapour transmission, moisture uptake and $\%$ moisture content of all formulations were given in (Table 2). The \% swellability of the prepared formulations was found as $14.28 \pm 0.38$ to $48.34 \pm 0.42$. Films containing higher amount of PVP showed good water vapour transmission $\left(4.38 \pm 0.21 \mathrm{~g} . \mathrm{cm}^{2} /\right.$ day X10 $\left.10^{-4}\right)$ than that of Eudragit and Ethyl cellulose films. All the formulations were permeable to water vapour. From the moisture content studies, all the formulations showed below $5 \%$ moisture content and moisture uptake.

\section{Diffusion study-in vitro release}

The cumulative percentage of drug permeated from the film of different formulations is shown in Figure 1. PVA:PVP transdermal films showed good in drug release when compared to ethyl cellulose and eudragit formulations. The percentage release was found to be highest $(99.12 \pm 0.96 \%)$ for formulation carrying PVA: PVP in ratio 1:4 when compared to other formulations.

\section{Ex vivo permeation studies}

The Ex vivo permeation studies were conducted for all formulations. The cumulative amount permeated was calculated and presented in Figure 2. The cumulative percent drug permeation was higher in case of PVA-PVP polymer containing matrix i.e. $73.28 \pm 0.92 \%$. The comparison between in vitro and ex vivo release from $\mathrm{F} 6$ formulation was given in Figure 3. The permeability coefficients were found in the range of 0.528 to 0.748 . The calculated flux and permeability coefficients of all formulations were shown in Figure 4. 
Table 2 Physical evaluation data of OSH Transdermal films

\begin{tabular}{|c|c|c|c|c|c|c|c|c|}
\hline $\begin{array}{l}\text { Formulation } \\
\text { code }\end{array}$ & $\begin{array}{l}\text { Weight } \\
\text { variation } \\
\text { (mg) }\end{array}$ & $\begin{array}{l}\text { Thickness } \\
(\mathrm{mm})\end{array}$ & $\begin{array}{l}\text { Folding } \\
\text { endurance }\end{array}$ & $\begin{array}{l}\text { (\%) Moisture } \\
\text { uptake }\end{array}$ & $\begin{array}{l}(\%) \\
\text { Moisture } \\
\text { content }\end{array}$ & $\begin{array}{l}\text { WVT rate } \\
\text { (g.cm } 2 / \text { day) } \\
x \mid 0^{-4}\end{array}$ & $\begin{array}{l}\text { Drug } \\
\text { content (\%) }\end{array}$ & $\begin{array}{l}\text { Swellability } \\
\text { (\%) }\end{array}$ \\
\hline $\mathrm{FI}$ & $66.12 \pm 1.8$ & $24 \pm 1.6$ & $71 \pm 0.9$ & $3.89 \pm 0.86$ & $3.28 \pm 0.75$ & $2.62 \pm 0.16$ & $97.45 \pm 0.21$ & $14.28 \pm 0.38$ \\
\hline F2 & $66.45 \pm 1.8$ & $26 \pm 1.6$ & $72 \pm 1.1$ & $4.85 \pm 0.91$ & $3.32 \pm .058$ & $2.93 \pm 0.16$ & $98.4 I \pm 0.34$ & $16.34 \pm 0.42$ \\
\hline F3 & $65.48 \pm 1.6$ & $25 \pm 1.6$ & $7 I \pm 0.9$ & $4.27 \pm 1.17$ & $4.92 \pm 1.38$ & $3.35 \pm 0.18$ & $99.17 \pm 0.38$ & $22.01 \pm 0.38$ \\
\hline $\mathrm{F} 4$ & $64.53 \pm 1.5$ & $36 \pm 1.3$ & $78 \pm 2.2$ & $4.65 \pm 0.4$ & $4.62 \pm 0.5$ & $4.16 \pm 0.28$ & $97.46 \pm 0.72$ & $44.86 \pm 0.64$ \\
\hline F5 & $64.21 \pm 1.4$ & $37 \pm 1.4$ & $77 \pm 2.0$ & $4.83 \pm 0.6$ & $4.92 \pm 0.8$ & $4.28 \pm 0.24$ & $98.74 \pm 0.39$ & $46.38 \pm 0.39$ \\
\hline F6 & $64.83 \pm 1.5$ & $37 \pm 1.3$ & $77 \pm 1.2$ & $4.96 \pm 0.4$ & $4.87 \pm 0.6$ & $4.38 \pm 0.21$ & $99.83 \pm 0.74$ & $48.34 \pm 0.42$ \\
\hline F7 & $67.91 \pm 1.7$ & $45 \pm 1.7$ & $77 \pm 1.1$ & $4.68 \pm 0.6$ & $3.26 \pm 0.3$ & $3.82 \pm 0.12$ & $96.75 \pm 0.48$ & $35.48 \pm 0.45$ \\
\hline F8 & $68.08 \pm 1.7$ & $47 \pm 1.9$ & $80 \pm 2.2$ & $4.86 \pm 0.8$ & $3.53 \pm 0.6$ & $3.91 \pm 0.13$ & $96.8 I \pm 0.4 I$ & $32.87 \pm 0.46$ \\
\hline F9 & $68.36 \pm 1.8$ & $46 \pm 1.8$ & $79 \pm 2.1$ & $4.53 \pm 0.8$ & $3.34 \pm 0.3$ & $4.15 \pm 0.11$ & $98.84 \pm 0.56$ & $30.13 \pm .055$ \\
\hline
\end{tabular}

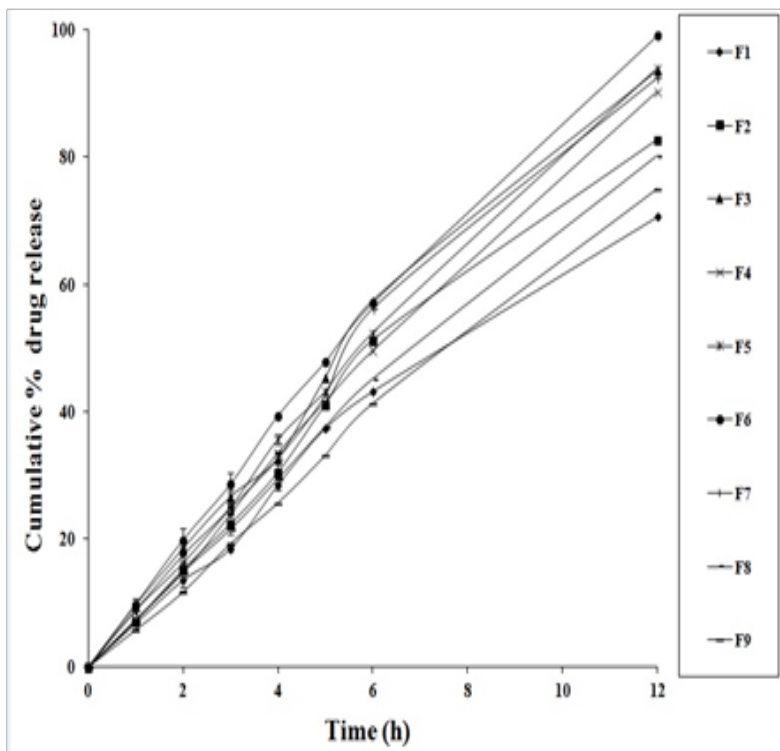

Figure I In vitro drug release profile of $\mathrm{OSH}$ from trans-dermal films $(\mathrm{n}=3$; Mean \pm SD).

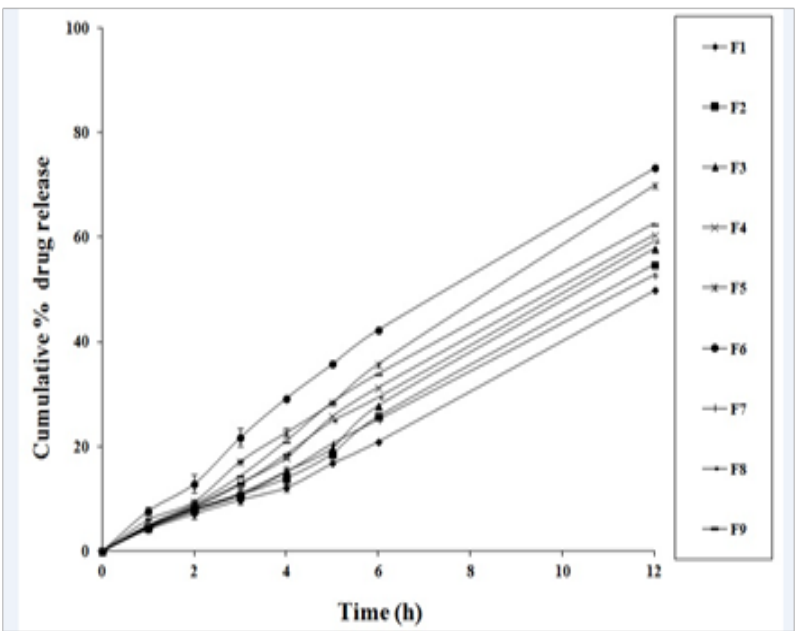

Figure 2 Ex vivo drug release profile of $\mathrm{OSH}$ from trans-dermal films $(n=3$; Mean \pm SD).

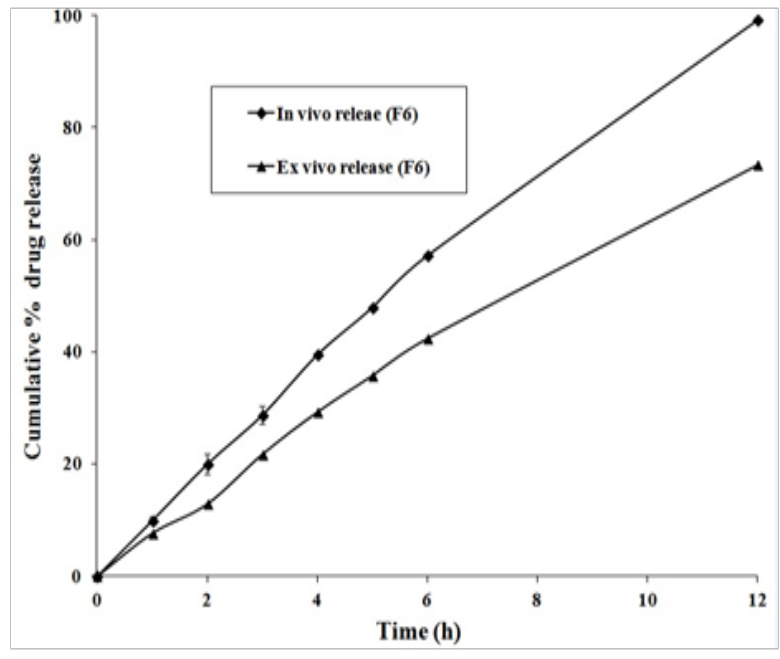

Figure 3 Comparison of in vitro and ex vivo drug release from OSH transdermal films $(n=3$; Mean \pm SD).

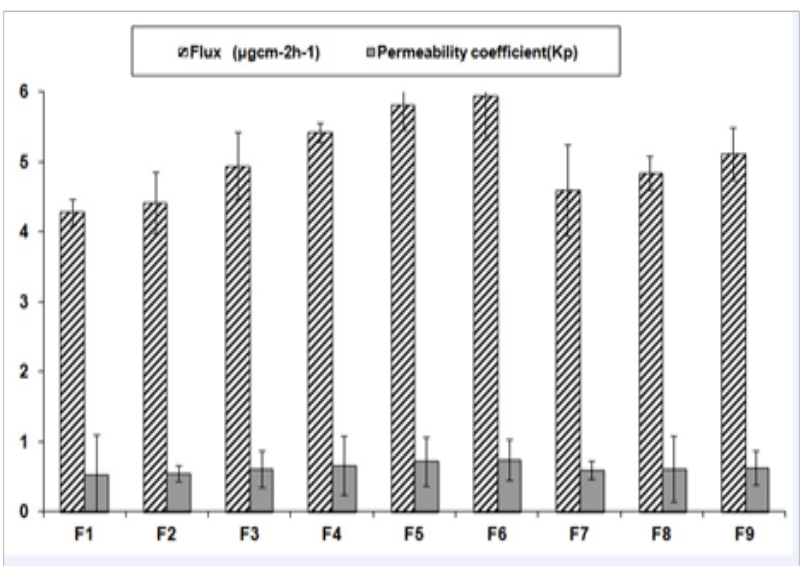

Figure 4 Ex vivo skin permeation steady state flux, permeability coefficients of trans-dermal films $(n=3 ;$ Mean $\pm S D)$.

\section{Kinetic modelling of drug release}

To analyze the OSH release mechanism as well as to select the matrix layer for formulation, in vitro release data were fitted into various release equations and kinetic models like first order, zero 
order, Higuchi and Korsmeyer and Peppas. Thus, it may be concluded that drug release from OSH matrix films is best explained by the Korsmeyer and Peppas model and zero order. The value of the slope indicates that the drug released by zero order type as shown in Table 3.

\section{Drug-excipients interactions}

DSC thermograms of plain drug, formulation and placebo film were shown in Figure 5. The characteristic peaks of pattern followed the same path as that of the drug alone with minor difference due to dilution effect.

Table 3 Kinetics data of formulation $\mathrm{F}_{6}$ OSH Transdermal films

\section{Stability studies}

Stability studies were carried out at $45^{\circ} \mathrm{C}$ and $75 \% \mathrm{RH}$ for three months to assess their stability. After storage, the formulation was subjected to drug content and in vitro release studies Table 4 . The calculated similarity index value between dissolution profiles of $\mathrm{F}_{6}$ formulation before and after storage was found to be 88.76 , which is more than 50 indicates similarity between the dissolution profile before and after storage. From the statistical analysis there was no significant difference between before and after storage $(\mathrm{P}<0.05)$.

\begin{tabular}{|c|c|c|c|c|c|}
\hline \multirow[t]{2}{*}{ Formulation parameter } & \multirow[t]{2}{*}{ Zero order model $\left(\mathbf{R}_{2}\right)$} & \multirow{2}{*}{$\begin{array}{l}\text { First order model } \\
\left(R_{2}\right)\end{array}$} & \multirow[t]{2}{*}{ Higuchi model $\left(\mathbf{R}_{2}\right)$} & \multicolumn{2}{|c|}{ Peppas model } \\
\hline & & & & $\mathbf{n}$ & $\mathbf{R}_{2}$ \\
\hline In vivo release & 0.995 & 0.776 & 0.999 & 0.823 & 0.998 \\
\hline Ex vivo release & 0.999 & 0.789 & 0.986 & 0.778 & 0.993 \\
\hline
\end{tabular}

Table 4 Stability studies of $F_{6}$ formulation before and after 3 months

\begin{tabular}{lllll}
\hline Time $(\mathbf{h})$ & Before storage & After $\mathbf{3}$ months storage & t-test at $\mathbf{0 . 0 5}$ LS & Similarity factor \\
\hline 0 & $0.0 \pm 0.0$ & $0.0 \pm 0.0$ & Not Significant & 88.76 \\
1 & $9.92 \pm 0.69$ & $8.78 \pm 0.89$ & & \\
2 & $19.98 \pm 1.78$ & $18.67 \pm 0.56$ & & \\
3 & $28.73 \pm 1.65$ & $28.42 \pm 1.15$ & & \\
4 & $39.48 \pm 0.12$ & $38.78 \pm 0.78$ & & \\
5 & $47.91 \pm 0.36$ & $46.64 \pm 1.26$ & & \\
6 & $57.16 \pm 0.77$ & $55.98 \pm 0.24$ & & \\
12 & $99.12 \pm 0.96$ & $98.31 \pm 0.78$ & Not Significant & - \\
Assay (\%) & $99.83 \pm 0.74$ & $98.42 \pm 0.54$ & & \\
\hline
\end{tabular}

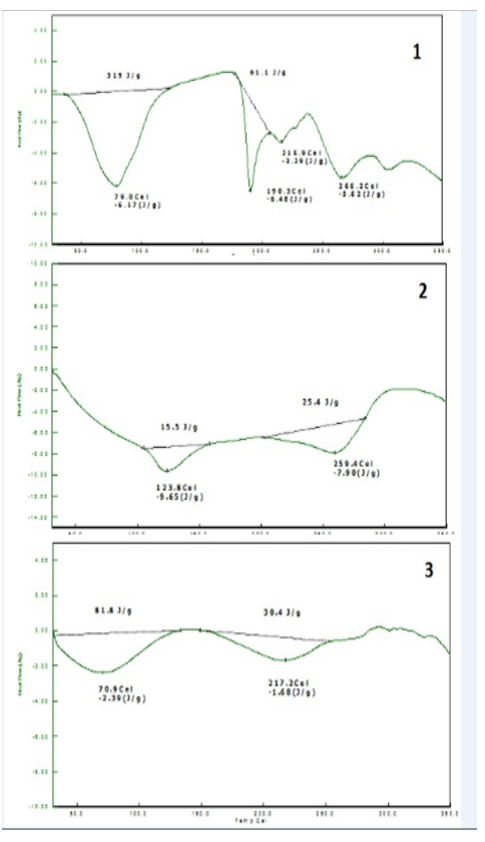

Figure 5 DSC thermo-gram of
a. Pure drug
b. F6 formulation
c. Dummy formulation

\section{Discussion}

The present study is aimed to formulate the OSH transdermal films to overcome the first pass hepatic metabolism. In this study OSH transdermal films were prepared by the solvent evaporation technique using ethyl cellulose, eudragit $\mathrm{RL}_{100}$, eudragit $\mathrm{RS}_{100}$, polyvinyl pyrrolidone and polyvinyl alcohol. The prepared transdermal films were evaluated for various physical characteristics. From the evaluation all the films were found to be uniform in the weight variation, thickness and drug content uniformity. The results of folding endurance specified that the films would not break and maintain their integrity with general skin folding. The folding endurance of eudragit films is higher than films containing ethyl cellulose and PVA-PVP.

From the film evaluation, the values of \% swellability, water vapour transmission, moisture uptake and $\%$ moisture content of all formulations were in the acceptable range. The study of hydration of polymers is an important finding that regulates the drug release from controlled/sustained release matrix. The result of water uptake by the polymer causes empty spaces within the film that could decrease its mechanical integrity and becomes structure less. The effect of hydration and water uptake is more common in hydrophilic polymers, so films containing higher amount of PVP showed good water vapour transmission than that of eudragit and ethyl cellulose films. PVP films showed the more water vapour permeation as a result of the irregular arrangement of molecules in the amorphous state, which causes the molecules to be spaced further apart than in crystal. From the moisture content studies, all the formulations showed below $5 \%$ 
moisture content and moisture uptake. Similar type of results was observed in a study developed by Fatima et al. ${ }^{11}$ As the moisture content of the prepared formulations was low, that results the more stable formulations with reduced brittleness, bulkiness and microbial contamination during long term storage..$^{22}$

From the in vivo drug release studies, the percentage drug release was found to be highest for formulation made up of PVA: PVP in ratio 1:4 due to the hydrophilic nature of polymer. Drug release from transdermal films is not only controlled by the chemical properties of the drug and delivery form but also by physiological and physicochemical properties of the biological membrane. Diffusion is the major pathway of drug release in most controlled release devices and is strongly influenced by polymer matrix as the motion of a small molecule is restricted by the three dimensional network of polymer chains. The drug release from OSH matrix films is best explained by the Korsmeyer and Peppas model and zero order. Similar kinds of results were observed in a study developed by Keith, 1983 using different matrix systems. ${ }^{3}$

From the ex vivo skin permeability studies, the cumulative percent drug permeation was higher in case of PVA-PVP polymer containing matrix due to hydrophilic nature of the polymers that initiates leaching of PVP and pore formation. This leads to an increase in the external film area exposed to the solvent, increased internal porosity and decreased tortuosity. Another reason of enhancement of skin flux with increase of PVP in the films is anti nucleating effect of PVP converts crystalline drug into high energetic and soluble amorphous state and its co enhancing property in aqueous vehicle system. The film made up of EC: PVP showed the slowest permeation due to the hydrophobic nature of the polymer which helps to retain the drug in the matrix by reducing the penetration of the solvent molecules into the film. On the basis of the ex vivo skin permeability studies, it appears that menthol at a concentration of $5 \% \mathrm{w} / \mathrm{w}$ is effective for enhancing the transdermal transport of OSH. If the drugs are intended for delivery to humans, the most appropriate setting in which to do the assessment is the in vivo human. However, this may not be possible for ethical, practical, or economic reasons, particularly in the early phases of development. Hence it is necessary to find alternative methods. Skin of rodents (mice, rats, guinea pigs etc) is the most commonly used in in-vitro percutaneous permeation studies, due to its availability, their small size, and relatively low cost. There are different hairless strains of each species that are reported to mimic the permeation properties of human skin better than the hairy variety. Among rodents, rat skin is most structurally similar to human skin and it is the most frequently used rodent model. ${ }^{23}$

The results of DSC thermograms of plain drug, formulation and placebo film were shown that there were no possible interactions between them. From the stability studies, after storage, the best formulation $\left(\mathrm{F}_{6}\right)$ films showed that there was no significant change in the drug content and in vitro release studies. From the statistical analysis there was no significant difference between before and after storage $(\mathrm{P}<0.05)$. The calculated similarity index value between dissolution profiles of $\mathrm{F}_{6}$ formulation before and after storage was found to be more than 50 indicate similarity between the dissolution profile before and after storage. ${ }^{24}$

\section{Conclusion}

$\mathrm{OSH}$, an anti-emetic drug has been selected which has half-life of 5-6h, the drug undergoes first pass hepatic metabolism. Hence in the current study, an attempt was made to provide transdermal drug delivery using water soluble and water insoluble polymers with $\mathrm{OSH}$ as the model drug. DSC study shows that there is no incompatibility between drug and polymers. The transdermal films were prepared using solvent casting method using combination of EC, PVP, PVA and eudragit in various ratios using dibutyl phthalate as plasticizer and menthol as a permeation enhancer. The F6 formulation (PVA: $\mathrm{PVP}=1: 4)$ shows optimum diffusion in concentration independent manner. The above formulation gave a maximum drug diffusion of $73.28 \%$ over a period of $12 \mathrm{~h}$. Higuchi's plot for the formulation revealed that the predominant mechanism of drug release is diffusion. However from peppa's plot the n value for F6 was indicating nonfickian diffusion. As an extension of this work pharmacokinetic studies and controlled clinical studies on human beings can be carried out in future.

\section{Acknowledgements}

The authors acknowledge the Sun Pharmaceuticals, Baroda, India for gift samples. The authors also thank to Management Chaitanya College of Pharmacy Education and Research for providing facilities.

\section{Conflict of interest}

The author declares no conflict of interest.

\section{References}

1. Misra AN. Controlled and novel drug delivery. In: Jain NK, editor. Trans-dermal drug delivery. CBS Publisher and Distributor, New Delhi, India; 1997. p. 100-101.

2. Chien YW. Trans-dermal therapeutic system. In: Robinson JR, Lee VHL, editors. Controlled drug delivery fundamentals and applications. Marcel Dekker, New York, USA; 1987. p. 524-552.

3. Keith AD. Polymer matrix consideration for trans-dermal devices. Drug Development and Industrial Pharmacy. 1983;9(4):605-625

4. Aquil M, Sultana Y, Ali A. Matrix type trans-dermal drug delivery systems of metoprolol tartrate: In vitro characterization. Acta Pharm. 2003;53(2):119-125.

5. Aquil M, Zafar S, Ali A, et al. Trans-dermal drug delivery of labetolol hydrochloride: System development, in vitro, ex vivo, and in vivo characterization. Curr Drug Deliv. 2005;2(2):125-131.

6. Singh J, Tripathi KP, Sakya TR. Effect of penetration enhancers on the in vitro transport of ephedrine through rat skin and human epidermis from matrix based trans-dermal formulations. Drug Development and Industrial Pharmacy. 1993;19(13):1623-1628.

7. Valenta C, Almasi-Szabo I. In vitro diffusion studies of ketoprofen transdermal therapeutic system. Drug Development and Industrial Pharmacy. 1995;21(15):1799-1805.

8. Shin SC, Lee HJ. Enhanced trans-dermal delivery of triprolidine from the ethylene-vinyl acetate matrix. Eur J Psharm Biopharm. 2002;54(3):325-328.

9. Gannu R, Vishnu YV, Kishan V, et al. Development of nitrendipine trans-dermal patches: In vitro and ex vivo characterization. Curr Drug Deliv. 2007;4(1):69-76.

10. Krishna R, Pandit JK. Trans-dermal delivery of Propranolol. Drug Development and Industrial Pharmacy. 1994;20(15):2459-2465.

11. Farsiya Fathima, Vijaya Kumar B, Shashi Ravi Suman Rudrangi, et al. Formulation and evaluation of matrix-type transdermal delivery system of ondansetron hydrochloride using solvent casting technique. Research J Pharm and Tech. 2011;4(5):806-814. 
12. Rajabalaya R, Chen DS, David SRN. Development of trans-dermal ondansetron hydrochloride for the treatment of chemotherapy-Induced nausea and vomiting. Trop J Pharm Res. 2013;12(3):279-285.

13. Patel RP, Patel G, Baria A. Formulation and evaluation of trans-dermal patch of aceclofenac. International Journal of Drug Delivery. 2009;1(1):41-51.

14. Kumar JA, Pullakandam N, Prabu SL, et al. Trans-dermal drug delivery system: an overview. International Journal of Pharmaceutical Sciences Review and Research. 2010;3(2):49-54.

15. Keleb E, Sharma RK, Mosa EB, et al. Trans-dermal drug delivery system-Design and evaluation. International Journal of Advances in Pharmaceutical Sciences. 2010;1(3):201-211.

16. Veerareddy PR, Vemula SK. Formulation, evaluation and pharmacokinetics of colon targeted pulsatile system of flurboprofen. J Drug Target. 2012;20(8):703-714.

17. Ravi V, Siddaramaiah, Pramod Kumar TM. Influence of natural polymer coating on novel colon targeting drug delivery system. J Mater Sci Mater Med. 2008;19(5):2131-2136.

18. Chaudhary A, Tiwari N, Jain V, et al. Microporous bilayer osmotic tablet for colon-specific delivery. Eur J Pharm Biopharm. 2011;78(1):134 140 .
19. Mathews BR. Regulatory aspects of stability testing in Europe. Drug Dev Ind Pharm. 1999;25(7):831-856.

20. Vemula SK, Bontha VK. Colon targeted gaur gm compression coated tablets of flrbiprofen: Formlation, development and pharmacokinetics. Biomed Res Int. 2013:287919.

21. Vemula SK, Veerareddy PR. Development, evaluation and pharmacokinetics of time-dependent ketorolac tromethamine tablets. Expert Opinion on Drug Delivery. 2013;10(1):33-45.

22. Mutalik S, Udupa N. Glibenclamide transdermal patches:physicochemical, pharmacodynamic, and pharmacokinetic evaluations. J Pharm Sci. 2004;93(6):1577-1594.

23. Simon GA, Maibach HI. Relevance of hairless mouse as an experimental model of percutaneous penetration in man. Skin Pharmacol Appl Skin Physiol. 1998;11(2):80-86.

24. Vemula SK, Veerareddy PR, Devadasu VR. Pharmacokinetics of colonspecific $\mathrm{pH}$ and time-dependent flurbiprofen tablets. Eur J Drug Metab Pharmacokinet. 2015;40(3):301-311. 